\title{
Effects of water deprivation on dry licking for shock avoidance and food reinforcement in the rat
}

\author{
GERALD A. YOUNG \\ University of Maryland, Baltimore, Maryland 21201 \\ and \\ ABRAHAM H. BLACK \\ McMaster University, Hamilton, Ontario, Canada
}

\begin{abstract}
One group of rats was trained on a signaled free-operant avoidance procedure to dry lick on a tungsten rod (lickometer) in order to avoid shock while water deprived or satiated. Avoidance performance was poor, and water deprivation level had no significant effect on licking performance. A second group of rats was operantly conditioned to dry lick for food pellets while water deprived or satiated. Licking for food reinforcement was effective, and there was a significant effect of water deprivation level on licking performance. The data suggest that effective licking for shock avoidance must be supported by fluid ingestion and that dry licking for food reinforcement is affected by other consequences in addition to food rewards.
\end{abstract}

We have previously shown that effective operant licking on a drinkometer spout must be supported by factors related to water regulation and taste palatability (Black \& Young, 1972; Young \& Black, 1977). The most effective licking for shock avoidance occurred while rats were water deprived and ingesting 10\% sucrose. Avoidance licking was less efficient when the same rats were water satiated and ingesting deionized water or isotonic saline. Similar interactions between operant licking and factors related to water regulation and taste palatability occurred during operant licking for food pellets. In contrast, it was demonstrated that leverpressing for shock avoidance or food pellets was not influenced by water deprivation level. Preliminary data was reported that indicated that effective licking on a drinkometer spout while ingesting a fluid did not transfer to licking either on a tungsten rod (lickometer) or at a stream of air (Young \& Black, 1977). The present study extends this data to a comparison of the effects of water deprivation level on licking on a lickometer (dry licking) to avoid electrical shocks or to receive food pellets.

The research for Experiment 1 was supported by Grant 258 from the Ontario Mental Health Foundation, Grant 70-476 from the Foundation's Fund for Research in Psychiatry, and Grant APA-0042 from the National Research Council of Canada to A. H. Black. The writing of this paper was interrupted by the untimely death of A. H. Black. The first author was fortunate to have been both a student and friend of Abe Black. Requests for reprints should be sent to G. A. Young, Department of Pharmacology and Toxicology, University of Maryland School of Pharmacy, 636 West Lombard Street, Baltimore, Maryland 21201.

\section{EXPERIMENT 1}

\section{Method}

Subjects. The subjects were six experimentally naive male Sprague-Dawley rats, each weighing approximately $275 \mathrm{~g}$ at the beginning of the experiment. Each rat was individually housed, and Purina Rat Chow and water were available in the home cages, except during water deprivation periods that will be described later.

Apparatus. The rats were trained in a modified Gerbrands Model C Skinner box that was situated in a sound-attenuated room. A lickometer $3.5 \mathrm{~cm}$ from the front of the Skinner box and $10.2 \mathrm{~cm}$ from the grid floor was located in the middle of a $2.5-\mathrm{cm}$-interdiameter circular hole in the right-hand wall. The lickometer (Wall, Walters, \& England, 1972) consisted of a 1/8-in.-diam tungsten rod coated with an insulating layer of glass, except for a small exposed area on the underside of the tip. Feedback from each lick was provided by the click of a $150-\mathrm{msec}$ closure of a $24-\mathrm{V}$ dc $300-\mathrm{ohm}$ relay.

Shocks, $150 \mathrm{msec}$ in duration, were delivered by a modified constant-current shock generator in conjunction with a recording attenuator that delivered shocks on a linear scale from 0 to $1.0 \mathrm{~mA}$. Before shocks were delivered, an 18-point relay switched the ground of the lickometer out of the circuit and the output of the shock generator into the circuit.

The discriminative stimulus $\left(S^{D}\right)$ was provided by a $75-d B$ re $20 \mathrm{uN} / \mathrm{m}^{2}$ click generator operating at a frequency of $5 \mathrm{~Hz}$ through an $8.9-\mathrm{cm}$-diam $4-\mathrm{ohm}$ speaker located $3.8 \mathrm{~cm}$ behind the right-hand wall of the Skinner box.

Data were collected with a six-pen event recorder and a printout counter. Sessions were monitored with a video camera and monitor.

Procedure. Each rat was initially trained while 22-h water deprived to avoid shocks on a Sidman schedule by licking $10 \%$ sucrose solution $(w / v)$ in the presence of the $S^{D}$. The responseshock (R-S) interval was $10 \mathrm{sec}$ and the shock-shock (S-S) interval was $1.35 \mathrm{sec}$. During each daily session, eight separate 5 -min $S^{D_{S}}$ were presented; intertrial intervals (ITIs) were $128 \mathrm{sec}$. The first shock in each $\mathrm{S}^{\mathrm{D}}$ presentation was scheduled 
to occur $10 \mathrm{sec}$ after the $\mathrm{S}^{\mathbf{D}}$ onset. During each $\mathrm{S}^{\mathrm{D}}$ period, the shock level began at zero intensity and increased linearly during $108 \mathrm{sec}$ of cumulative S-S time to a maximum of $1.0 \mathrm{~mA}$. After stable levels of avoidance responding were established (7 to 10 sessions), each rat was run for 4 consecutive days while water satiated and for 4 days while $22-h$ water deprived. Three rats were run first while water satiated; the other three rats were run first while water deprived.

Measurements were taken of dry licking rates during $S^{D}$ and ITI periods and of the number of shocks received during each experimental session. The rejection level for all statistical analyses was set at the $5 \%$ level.

\section{Results}

While $22 \cdot \mathrm{h}$ water deprived and ingesting $10 \%$ sucrose during the last day of training, the six rats averaged $53.0 \pm 2.0$ (mean \pm SEM) licks/min during $\mathrm{S}^{\mathrm{D}}$ presentations and $16.4 \pm 1.2$ licks/min during ITIs. The rats also received an average of $671 \pm 83$ shocks/session. All of these values are similar to those previously reported for the same experimental conditions (Young \& Black, 1977). Since there were no differences in licking performances over the 4 consecutive days of each experimental condition, the data were examined and compared on the final (4th) day of each condition. While water deprived, the rats averaged $3.0 \pm 3.2$ licks $/ \mathrm{min}$ during $\mathrm{SD}_{\mathrm{S}}$ and $.1 \pm 0$ licks/min during ITIs. While water satiated, the subjects averaged $2.5 \pm 2.7$ licks/min during $\mathrm{SD}_{\mathrm{s}}$ and $.2 \pm .2$ licks/min during ITIs. The rats also received an average of $1,527 \pm 107$ shocks/session while water satiated and 1,595 \pm 142 shocks/session while water deprived. Analyses of variance indicated that none of the experimental variables significantly influenced licking rates or number of shocks received per session.

\section{Discussion}

Effective avoidance responding on the drinkometer spout while the rats were 22-h water deprived and ingesting $10 \%$ sucrose did not transfer to dry licking. Although one might argue that $\mathbf{8}$ days of experience with dry licking was not enough to generate asymptotic levels of performance, there was no difference between performances during the first and eighth experimental sessions. Furthermore, the subjects had the experience of avoiding shocks by licking and ingesting $10 \%$ sucrose prior to dry licking. Dry licking was also not influenced by water deprivation level. If an inhibitory interaction had occurred between an appetitive motivational system associated with licking and an aversive motivational system associated with shock presentation, one would expect, contrary to the findings, water deprivation level to affect dry licking performance.

Perhaps the relatively poor avoidance performance while licking on the lickometer was due to a contrast effect. The subjects were initially trained to avoid shocks while ingesting $10 \%$ sucrose, which is normally a highly preferred substance. The subsequent shift to having the opportunity to dry lick could account for the deterioration in performance if the lickometer was a less preferred response target. However, an attempt was made to initially train several rats for several sessions to avoid shocks while licking on the lickometer. None of those rats developed licking rates that were higher than those found in the present study. During some of the sessions, the tip of the lickometer was even baited with a droplet of $10 \%$ sucrose.
The most obvious difference between dry licking and licking a drinkometer spout is the lack of fluid ingestion in the case of dry licking. Perhaps effective avoidance licking must be supported by fluid ingestion. It seemed relevant to study dry licking for positive reinforcement. This was done in Experiment 2 while employing the same experimental set-up.

\section{EXPERIMENT 2}

\section{Method}

Subjects. Four male Sprague-Dawley rats were used. Each rat was maintained at $80 \%$ of its normal free-feeding weight. Purina Rat Chow was administered in the home cages immediately after each experimental session to maintain the $80 \%$ weights.

Apparatus. The same equipment was used as that in the previous experiment.

Procedure. Each rat was initially trained to obtain $45-\mathrm{mg}$ Noyes pellets on a variable-interval 1-min schedule of reinforcement by dry licking while water satiated. After stable levels of licking were established (eight sessions), each subject was run for four further consecutive sessions while $22-\mathrm{h}$ water deprived and for four consecutive sessions while water satiated.

\section{Results}

During the last four training sessions while water satiated, the rats averaged $55.8 \pm 2.5$ licks $/ \mathrm{min}$. The data were further examined and compared during the 4 consecutive days the subjects were 22 -h water deprived and during the subsequent 4 consecutive days they were water satiated. An analysis of variance was carried out on the data in Figure 1, where average rates of licking during each day are compared for the two experimental conditions. The main treatment variables were deprivation level (water deprived vs. water satiated) and experi-

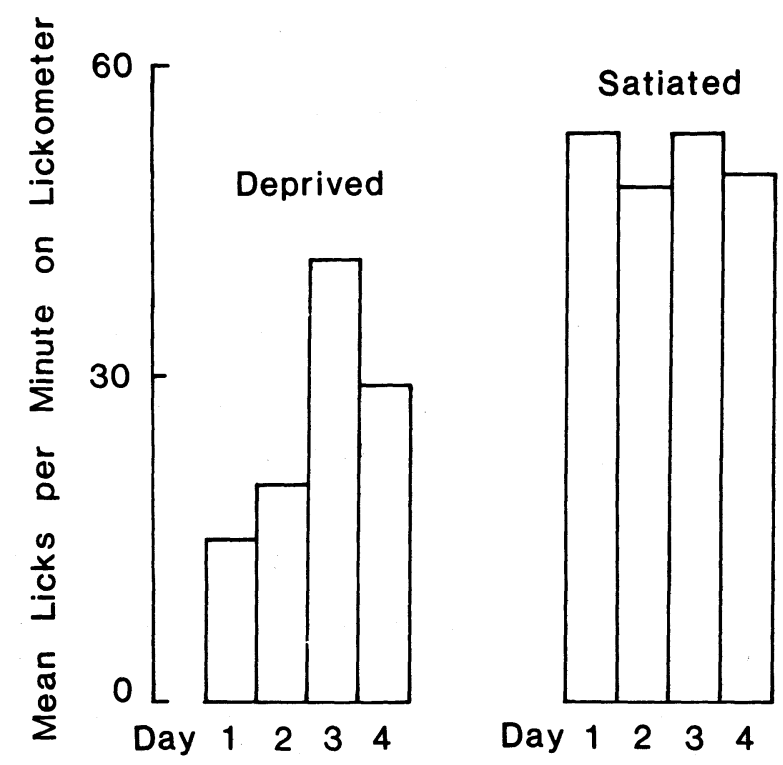

Figure 1. Grouped data for four rats showing mean operant licking rates for food reinforcement as a function of water deprivation level (22-h water deprived vs. water satiated) and experimental session (first through fourth). 
mental day (1st through 4th). There was a significant effect of deprivation level and experimental day on the average rate of licking. The rats licked more while water satiated $[\mathrm{F}(1,3)=13.25]$ and during the later experimental days $[F(3,9)=4.42]$. The Deprivation Level by Experimental Day interaction was also significant $[F(3,9)=16 \cdot 10]$. An examination of Figure 1 suggests that the interaction occurred because the average rates of licking varied over the 4 experimental days the rats were water deprived but did not significantly change over the 4 days the rats were water satiated.

\section{Discussion}

Licking on the lickometer for food pellets in our experimental situation was an effective operant. Effective licking on a lickometer for food (Walters \& Herring, 1978; Young, 1973) and water (Wall et al., 1972) reinforcement has been previously reported. Furthermore, dry licking for food pellets was more effective when the subjects were water satiated than when they were water deprived. Bolles (1967, pp. 203-206) suggested that inhibitory interaction might occur between motivational states produced by water deprivation and food deprivation. This could account for the present data. However, one must account for our previous findings that (1) water deprivation increased operant licking on a drinkometer spout for food reinforcement and (2) water deprivation level had no effect on leverpressing performance for food reinforcement (Young \& Black, 1977). In the case of the drinkometer spout, the rats were ingesting both food and water. Thus, motivational needs produced by water and food deprivation were relieved together, and any inhibitory interaction had been alleviated. In the case of leverpressing, the inhibitory interaction explanation does not seem to hold.

Other aspects of the data also need consideration. For example, it seems possible that the dry licking performance during water deprivation was relatively poor because the rats were still acquiring the licking response as an operant. However, since the licking rates were not only stabilized but also relatively higher during the preceding 4 days the subjects were water satiated, it seems unlikely that the rats were still in the process of learning to dry lick for food reinforcement. Since licking rates were comparable before and after the 4 days of water deprivation, the order of water deprivation and satiation did not seem to be an important factor.

\section{GENERAL DISCUSSION}

In the present experiments, dry licking was an efficient operant for food reinforcement but not for shock avoidance. One could argue that the motivation to avoid shock was lower than that to obtain food pellets, which could account for the difference in performance in the two situations. However, the difference seems too great to be accounted for solely by difference in motivational levels. Furthermore, it appears that effective operant licking for shock avoidance needs to be supported by the ingestion of a fluid. The reason for this is not clear.

One important difference exists between the effects of water deprivation level on dry licking for food reinforcement seen in the present study and those seen during licking on a drinkometer spout in earlier studies (Black \& Young, 1972; Young \& Black, 1977). With dry licking, rates were higher during water satiation than during water deprivation. In contrast, in the case of the drinkometer spout, rates of licking were higher during water deprivation than during satiation. These results suggest that the presence or absence of fluid ingestion interacted with water deprivation level. For example, it could be argued that operant licking while ingesting a fluid is facilitated by water deprivation because licking is not only being reinforced by food pellets, but is also relieving a state of water deprivation. In the case of dry licking, however, the rat is probably increasing its degree of water deprivation because its saliva is evaporating from the lickometer surface. Referring to the inhibitory effect of water deprivation on food intake, Bolles (1967) stated that "it could be argued that food loses palatability, because of dryness of the mouth." Thus, it could be argued that a water-satiated rat is less affected by saliva evaporation and, therefore, licks at a relatively higher rate.

In summary, we propose that the efficiency of licking as an operant not only interacts with factors related to water deprivation level and taste palatability (Young \& Black, 1977), but also is affected by other consequences, such as fluid ingestion, saliva evaporation, or, as previously suggested in the case of avoidance licking while ingesting a fluid (Young \& Black, 1977), urine retention. While other investigators have discussed constraints upon operant conditioning, they have emphasized constraints on the formation of associations between stimuli, responses, and reinforcers (Bolles, 1970; Garcia, McGowan, \& Green, 1972; Seligman, 1970; Shettleworth, 1972, 1975; Turner \& Solomon, 1962; Walters \& Herring, 1978). However, other performance constraints have been revealed in this and former studies (Black \& Young, 1972; Young \& Black, 1977) by manipulating variables related to water regulation and taste palatability after learning had already taken place.

\section{REFERENCES}

Black, A. H., \& Young, G. A. Constraints on the operant conditioning of drinking. In R. M. Gilbert \& J. R. Millenson (Eds.), Reinforcement: Behavioral analyses. New York: Academic Press, 1972.

Bolles, R. C. Theory of motivation. New York: Harper \& Row, 1967.

Bolles, R. C. Species-specific defense reactions and avoidance learning. Psychological Review, 1970, 77, 32-48.

Garcia, J., McGowan, B. K., \& Green, K. F. Biological constraints on learning. In A. H. Black \& W. K. Prokasy (Eds.), Classical conditioning II: Current theory and research. New York: Appleton, 1972.

Seligman, M. E. P. On the generality of the laws of learning. Psychological Review, 1970, 77, 406-418.

Shettleworth, S. J. Constraints on learning. Advances in the Study of Behavior, 1972, 4, 1-68.

Shettleworth, S. J. Reinforcement and the organization of behavior in golden hamsters: Hunger, environment and food reinforcement. Journal of Experimental Psychology: Animal Behavior Processes, 1975, 1, 56-87.

Turner, L. H., \& Solomon, R. L. Human traumatic avoidance learning: Theory and failure to learn. Psychological Monographs, 1962, 76(Whole No. 40).

Wall, A. M., Walters, G. C., \& England, R. S. The lickometer: A simple device for the analysis of licking as an operant. Behavior Research Methods \& Instrumentation, 1972, 4, 320-322.

Walters, G. C., \& Herring, B. Differential suppression by punishment of nonconsummatory licking and lever pressing. Journal of Experimental Psychology: Animal Behavior Processes, 1978, 4, 170-187.

Young, G. A. Relationships between hippocampal EEG and behavior in the rat. Unpublished doctoral dissertation, McMaster University, 1973.

Young, G. A., \& Black, A. H. A comparison of operant licking and lever pressing in the rat. Learning and Motivation, 1977, 8, 387-403.

(Received for publication June 4, 1979.) 